11,01

\title{
Формирование нанокристаллов в аморфной фазе многокомпонентных систем
}

\author{
(C) Г.Е. Абросимова, А.С. Аронин, Н.А. Волков \\ Институт физики твердого тела РАН, \\ Черноголовка, Россия \\ E-mail: gea@issp.ac.ru
}

Поступила в Редакцию 12 марта 2019 г.

В окончательной редакции 12 марта 2019 г.

Принята к публикации 12 марта 2019 г.

\begin{abstract}
Методами рентгенографии и просвечивающей электронной микроскопии исследовано влияние концентрации легирующих компонентов на кристаллизацию аморфных сплавов систем $\left(\mathrm{Fe}_{73} \mathrm{Si}_{13} \mathrm{~B}_{9}\right)_{1-x-y} \mathrm{Nb}_{x} \mathrm{Cu}_{y}$ и $\left(\mathrm{Co}_{70} \mathrm{Si}_{12} \mathrm{~B}_{9}\right)_{1-x-y} \mathrm{Fe}_{x} \mathrm{Nb}_{y}$ в широкой области составов. Показано, что образование ОЦК структуры в обеих группах сплавов существенно зависит от концентрации легирующих компонентов. Обнаружено образование ОЦК фазы в сплавах на основе кобальта в такой концентрационной области, где она не наблюдалась ранее. В исследованной группе сплавов на основе кобальта ОЦК фаза появляется при концентрации ниобия выше 1 at\%, средний размер ОЦК нанокристаллов меняется от $40 \mathrm{~nm}$ (при $1 \mathrm{at} \% \mathrm{Nb}$ ) до $14 \mathrm{~nm}$ (при 5 at.\% Nb). В сплавах на основе Fе нанокристллы с ОЦК решеткой образуются при концентрации меди 0.45-1 at.\%, средний размер нанокристаллов зависит от состава сплава и меняется в диапазоне $16-24 \mathrm{~nm}$. Обсуждаются причины концентрационной зависимости формирования наноструктуры в исследованных сплавах.
\end{abstract}

Ключевые слова: аморфная фаза, кристаллизация, нанокристаллы, просвечивающая электронная микроскопия, рентгенография.

DOI: 10.21883/FTT.2019.07.47850.415

\section{1. Введение}

Исследование наноструктур является одним из наиболее интересных направлений современной физики конденсированного состояния. Особенности структуры (размер кристаллов, составляющий несколько параметров решетки, морфология частиц, распределение нанокристаллов в аморфной матрице) определяют необычные физические свойства, отличающиеся от свойств традиционных материалов. В нанокристаллических материалах нарушается закон Петча-Холла, магнитные свойства частично кристаллических сплавов существенно отличаются от свойств аморфных и традиционных кристаллических материалов. Одним из основных методов получения нанокристаллических металлических материалов для большинства известных систем является контролируемая кристаллизация металлических стекол. К настоящему времени наноструктура была получена в широкой группе металлических систем, имеется ряд данных о параметрах нанокристаллической структуры, полученной разными методами [1-13]. Установлено, что кристаллизация аморфных металлических сплавов очень часто начинается с образования метастабильных кристаллических фаз, в некоторых системах может происходить одновременное образование нескольких метастабильных кристаллических фаз [14]), а в ряде случаев кристаллические фазы [15] могут сосуществовать с квазикристаллическими [16-18].
Как было отмечено, ряд нанокристаллических материалов обладает хорошими магнитными свойствами. К таким материалам относятся частичнокристаллические сплавы на основе железа и кобальта $[19,20]$. Нанокристаллические сплавы типа Finemet $\left(\mathrm{Fe}_{73.5} \mathrm{Si}_{13.5} \mathrm{~B}_{9} \mathrm{Nb}_{3} \mathrm{Cu}_{1}\right)$ обладают великолепным комплексом гистерезисных свойств, сплавы группы $\mathrm{Fe}-\mathrm{M}-\mathrm{B}$ $(M=\mathrm{Zr}, \mathrm{Hf}, \mathrm{Nb})$ имеют высокие значения индукции насыщения и магнитной проницаемости, аморфные сплавы на основе кобальта характеризуются высокой магнитной проницаемостью и магнитной восприимчивостью, ряд этих сплавов имеют нулевую константу магнитострикции. В зависимости от состава эти материалы характеризуются высокой намагниченностью насыщения, низкой коэрцитивной силой, высокой магнитной проницаемостью, малыми потерями на перемагничивание. Основой таких сплавов обычно являются составы $\mathrm{Fe}-\mathrm{Si}-\mathrm{B}$ и $\mathrm{Co}-\mathrm{Si}-\mathrm{B}$, которые легко могут быть получены в аморфном состоянии. Аморфные сплавы этих систем обладают хорошими магнитными характеристиками, и магнитные свойства могут быть заметно улучшены при формировании в аморфной фазе нанокристаллов железа или кобальта и образования таким образом композитной структуры, состоящей из нанокристаллов, хаотически распределенных в аморфной матрице. Однако путем термообработки сформировать наноструктуру в тройных сплавах не удается, поэтому в сплавы добавляют легирующие компоненты: $\mathrm{Cu}, \mathrm{Nb}, \mathrm{Zr}$ и др., способствующие увеличению скорости зарождения кристаллов в 
аморфной матрице и уменьшению скорости их роста. Было показано, что образование разных фаз в процессе кристаллизации таких сплавов [21-25] может приводить к кардинальным изменениям свойств.

В большинстве работ, посвященных изучению многокомпонентных сплавов на основе железа и кобальта, как правило, изучался фазовый состав частично или полностью закристаллизованных образцов и проводилось сопоставление фазового состава с магнитными свойствами. Однако свойства материала зависят не только от его химического и фазового состава, но и ряда других структурных параметров: размера нанокристаллов, доли нанокристаллической фазы, взаимного расположения структурных составляющих и др. В настоящей работе предпринято исследование фазовых превращений на начальной стадии кристаллизации аморфных сплавов на основе железа и кобальта и их зависимости от концентрации легирующих элементов.

\section{2. Методика эксперимента}

В работе исследованы две группы сплавов: сплавы на основе железа $\left(\mathrm{Fe}_{73} \mathrm{Si}_{13} \mathrm{~B}_{9}\right)_{1-x-y} \mathrm{Nb}_{x} \mathrm{Cu}_{y}$, содержащие $2-3$ at.\% $\mathrm{Nb}$ и 0-1 at.\% $\mathrm{Cu}$ и сплавы на основе кобальта $\left(\mathrm{Co}_{70} \mathrm{Si}_{12} \mathrm{~B}_{9}\right)_{1-x-y} \mathrm{Fe}_{x} \mathrm{Nb}_{y}$, содержащие 0.7 и 7 at.\% $\mathrm{Fe}$ и 0-5 at.\% Nb. Аморфные образцы были получены в виде лент толщиной 30-50 $\mu \mathrm{m}$ методом скоростной закалки расплава по одновалковой схеме. Ширина аморфных лент составляла около $1 \mathrm{~cm}$. Состав сплавов контролировался с помощью рентгеноспектрального анализа на сканирующем электронном микроскопе Zeiss Supra 50VP.

Образцы всех составов одновременно подвергались термообработке при температурах $400-700^{\circ} \mathrm{C}$ в течение разного времени в печи сопротивления. Структура образцов исследовалась методами рентгенографии и просвечивающей электронной микроскопии. Рентгеноструктурные исследования проводились на рентгеновском дифрактометре SIMENS D-500 с использованием Со $K_{\alpha}$-излучения. При обработке спектров использовались специальные программы, позволяющие проводить сглаживание, коррекцию фона, разделение перекрывающихся максимумов и др. Фольги для электронно-микроскопических исследований готовились ионным утонением. Размер образующихся нанокристаллов определялся как по темнопольным электронномикроскопическим изображениям, так и по данным дифрактометрии. Оценка размера нанокристаллов по полуширине дифракционной линии проводилась с использованием известной формулы Селякова-Шеррера [26].

\section{3. Результаты}

После закалки все образцы были аморфными. Изменения структуры при термообработке зависели от состава сплавов.

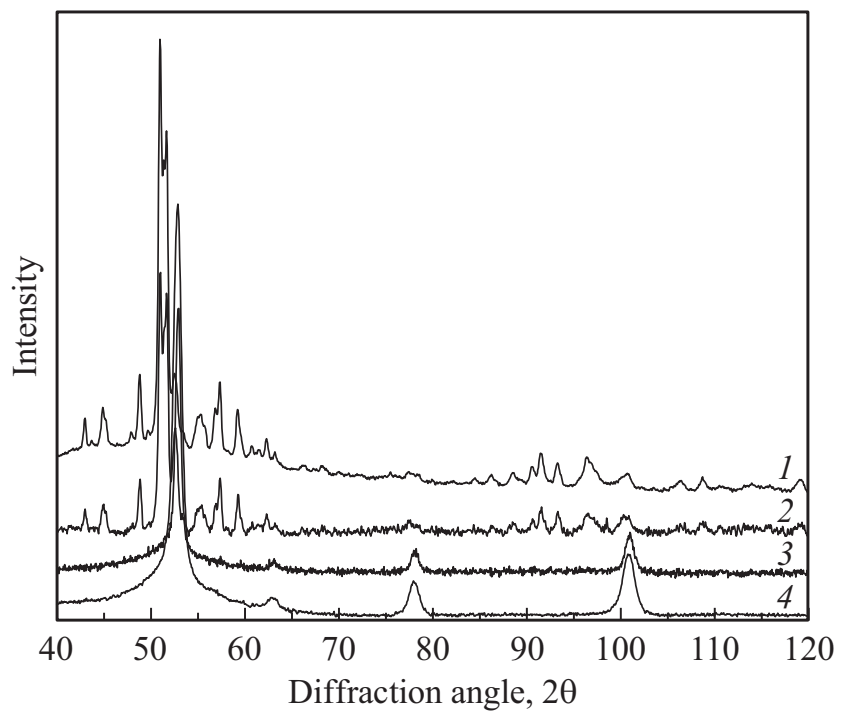

Рис. 1. Рентгенограммы сплавов на основе железа, отожженных при $550^{\circ} \mathrm{C}$ в течение $1 \mathrm{~h}\left(1-\mathrm{Fe}_{72.24} \mathrm{Si}_{13.63} \mathrm{~B}_{9.1} \mathrm{Nb}_{3.03}, 2-\right.$ $\mathrm{Fe}_{74.02} \mathrm{Si}_{13.59} \mathrm{~B}_{9.07} \mathrm{Nb}_{3.02} \mathrm{Cu}_{0.3}, 3-\mathrm{Fe}_{73.91} \mathrm{Si}_{13.57} \mathrm{~B}_{9.05} \mathrm{Nb}_{3.02} \mathrm{Cu}_{0.45}$, $\left.4-\mathrm{Fe}_{73.5} \mathrm{Si}_{13} \mathrm{~B}_{10.9} \mathrm{Nb}_{3} \mathrm{Cu}_{1}\right)$.

\section{1. Сплавы на основе железа}

Отжиг при температурах ниже $500^{\circ} \mathrm{C}$ не приводил к заметным изменениям структуры. После отжига при $500^{\circ} \mathrm{C}$ образцы сплавов на основе железа являлись частично кристаллическими. Фазовый состав частичнокристаллических образцов зависел от химического состава сплава. Сплавы, содержащие 0.45 и 1 at.\% меди, после отжига являлись двухфазными, и содержали нанокристаллы ОЦК фазы и оставшуюся аморфную матрицу. При повышении температуры отжига доля нанокристаллической фазы увеличивалась, изменения фазового состава при этом не наблюдалось. При уменьшении концентрации меди структура заметно изменялась: сплавы с 0.3 at.\% меди и безмедный наряду с оставшейся аморфной фазой содержали несколько кристаллических фаз. На рис. 1 приведены рентгенограммы сплавов после часового отжига при температуре $550^{\circ} \mathrm{C}$. В сплавах c 0.45-1 at.\% меди образования дополнительных кристаллических фаз обнаружено не было.

Средний размер нанокристаллов определялся по уширению дифракционных линий по формуле СеляковаШеррера и по темнопольным электронно-микроскопическим изображениям. Было установлено, что средний размер нанокристаллов увеличивается при уменьшении концентрации меди: после часового отжига при $550^{\circ} \mathrm{C}$ средний размер нанокристаллов в сплаве 0.45 at.\% Cu coставляет $24 \mathrm{~nm}$, а в сплаве с 1 at.\% $\mathrm{Cu}-16 \mathrm{~nm}$. Доля нанокристаллической фазы при увеличении концентрации меди заметно возрастает. С увеличением концентрации меди (при постоянной концентрации ниобия) также растет температура кристаллизации (термическая стабильность аморфной фазы увеличивается). При уменьшении 
концентрации меди ниже 0.4 at.\% нанокристаллическая ОЦК структура не образуется. Формирующаяся в этих сплавах структура также является нанокристаллической, но состоит из нескольких кристаллических фаз, средний размер нанокристаллов для разных фаз составляет $25-35 \mathrm{~nm}$.

\section{2. Сплавы на основе кобальта}

При исследовании процессов кристаллизации в сплавах на основе кобальта была также обнаружена зависимость микроструктуры от химического состава сплава. На рис. 2 показаны рентгенограммы сплавов на основе кобальта после отжига при $550^{\circ} \mathrm{C}$ в течение $1 \mathrm{~h}$.

Из рисунка видно, что сплав без ниобия (кривая 1 на рис. 2) является многофазным, его структура состоит из кристаллов нескольких фаз: ГПУ-Со, ГЦК-Со, $\mathrm{Co} 2 \mathrm{Si}, \mathrm{Co} 2 \mathrm{~B}$ и остаточной аморфной фазы. При добавлении 1 at.\% ниобия структура отожженного сплава резко изменяется. Отожженный образец (кривая 2, рис. 2) содержит следы фаз, присутствующих в образце без ниобия, основными фазами является кристаллическая фаза с ОЦК решеткой и аморфная фаза. При увеличении концентрации ниобия доля ОЦК фазы растет (кривая 3 на рис. 2 соответствует образцы с 2 at.\% Nb). В образце c 5 aт.\% $\mathrm{Nb}$ она является единственной кристаллической фазой (помимо аморфной фазы).

Таким образом, формирующаяся при кристаллизации структура существенно зависит от концентрации ниобия: в сплаве, содержащем 2 at.\% $\mathrm{Nb}$, после первой стадии кристаллизации структура является практически двухфазной и содержит помимо аморфной фазы только нанокристаллы ОЦК фазы (дополнительные фазы могут наблюдаться в следовом количестве). При уменьшении концентрации ниобия до $1 \%$ появляется небольшое

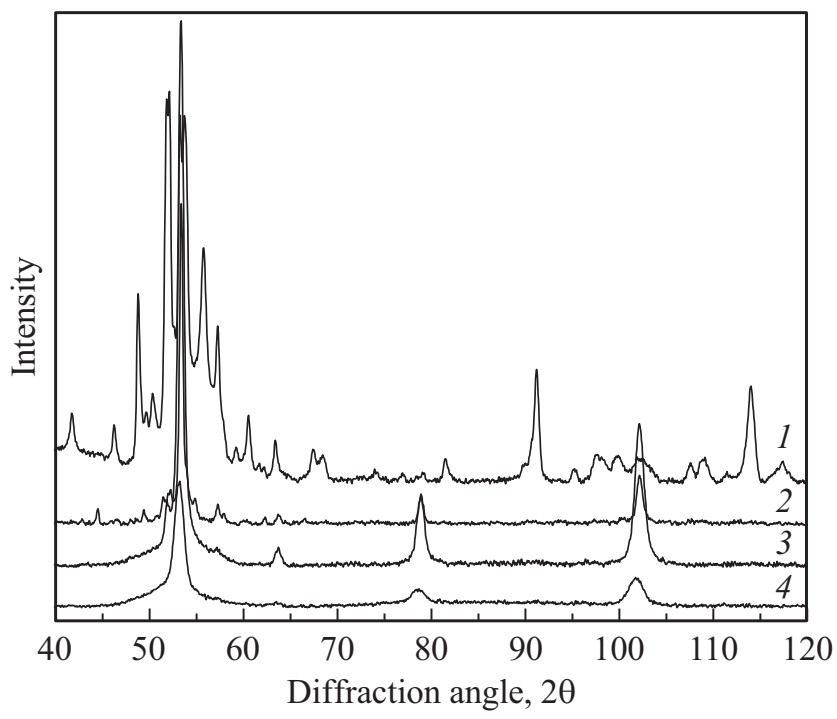

Рис. 2. Рентгенограммы сплавов на основе кобальта c 7 at.\% $\mathrm{Fe}$, отожженных при $550^{\circ} \mathrm{C}$ в течение $1 \mathrm{~h}(1-$ без ниобия, $2-1$ at.\% $\mathrm{Nb}, 3-2$ at.\% $\mathrm{Nb}, 4-5$ at.\% $\mathrm{Nb}$ ).

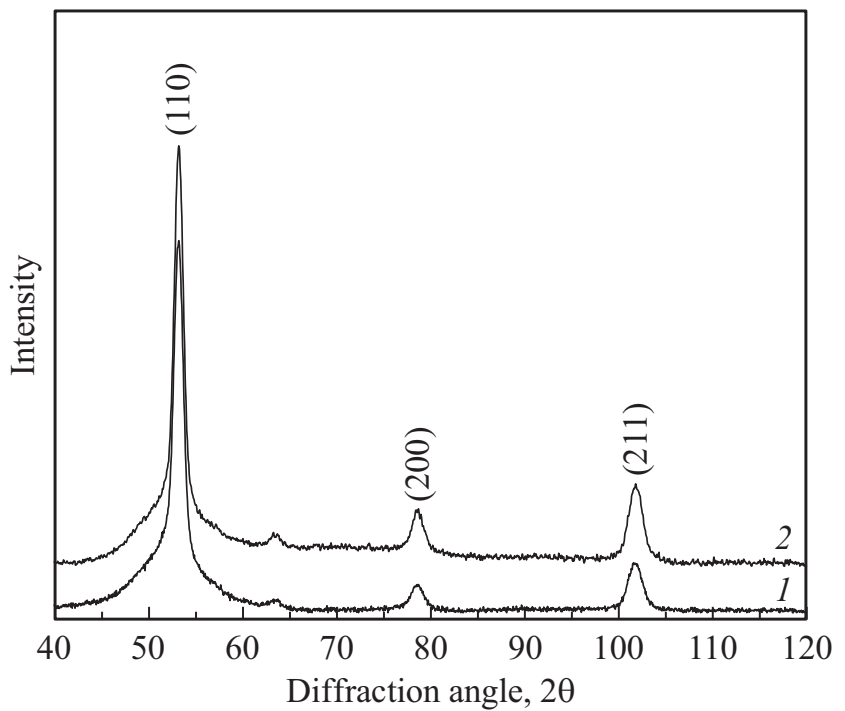

Рис. 3. Рентгенограмма сплава $\mathrm{Co}_{75.3} \mathrm{Si}_{12} \mathrm{~B}_{9} \mathrm{Fe}_{0.7} \mathrm{Nb}_{3}$ после отжига при $550^{\circ} \mathrm{C}$ в течение $1 \mathrm{~h}(1)$ и $3 \mathrm{~h}(2)$.

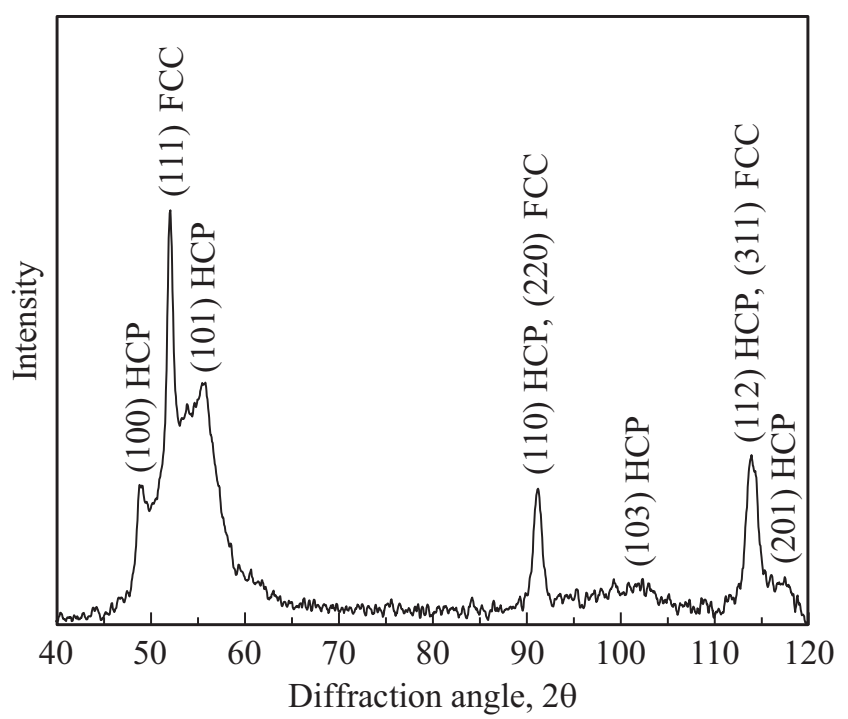

Рис. 4. Рентгенограмма сплава $\mathrm{Co}_{75.3} \mathrm{Si}_{12} \mathrm{~B}_{9} \mathrm{Fe}_{0.7} \mathrm{Nb}_{3}$ после часового отжига при $550^{\circ} \mathrm{C}$.

количество дополнительных кристаллических фаз, в то время как образец, не содержащий ниобия, после первой стадии кристаллизации уже является многофазным.

Как и в случае сплавов на основе железа, средний размер нанокристаллов определялся по уширению дифракционных линий по формуле Селякова-Шеррера и по темнопольным электронно-микроскопическим изображениям. Значения размеров и параметр решетки ОЦК фазы приведены в таблице. В пределах точности эксперимента параметр решетки можно считать неизменным.

Сформировавшаяся структура характеризуется высокой стабильностью. На рис. 3 приведены рентгенограммы сплава Co67Fe7Si12B9Nb5 после отжигов при $550^{\circ} \mathrm{C}$ в течение $1 \mathrm{~h}$ (кривая 1) и $3 \mathrm{~h}$ (кривая 2). Средний 
Зависимость фазового состава и размера нанокристаллов от химического состава сплава

\begin{tabular}{c|c|c|c|c}
\hline $\begin{array}{c}\text { Химический } \\
\text { состав }\end{array}$ & Концентрация, $\mathrm{Nb}$ & Фазовый состав & $\begin{array}{c}\text { Размер } \\
\text { нанокристаллов, nm }\end{array}$ & $\begin{array}{c}\text { Параметр } \\
\text { решетки, } \AA\end{array}$ \\
\hline $\mathrm{Co}_{72} \mathrm{Fe}_{7} \mathrm{Si}_{12} \mathrm{~B}_{9}$ & $0 \% \mathrm{Nb}$ & многофазный & - & \\
$\mathrm{Co}_{71} \mathrm{Fe}_{7} \mathrm{Si}_{12} \mathrm{~B}_{9} \mathrm{Nb}_{1}$ & $1 \mathrm{at} \% \mathrm{Nb}$ & ОЦК $+\ldots$ & 40 & 2.814 \\
$\mathrm{Co}_{70} \mathrm{Fe}_{7} \mathrm{Si}_{12} \mathrm{~B}_{9} \mathrm{Nb}_{2}$ & $2 \mathrm{at.} \% \mathrm{Nb}$ & ОЦК & 25 & 2.816 \\
$\mathrm{Co}_{67} \mathrm{Fe}_{7} \mathrm{Si}_{12} \mathrm{~B}_{9} \mathrm{Nb}_{5}$ & 5 at.\% Nb & ОЦК & 14 & 2.816
\end{tabular}

размер нанокристаллов составлял $14 \mathrm{~nm}$ и не зависел от длительности отжига, доля нанокристаллической фазы возрастает примерно на $30 \%$. При малом содержании железа $(0.7$ at.\%) ОЦК фаза не образуется. На рис. 4 показана рентгенограмма сплава, содержащего около 0.7 at.\% Fe. В этом сплаве на начальной стадии кристаллизации происходит образование нанокристаллов кобальта, причем в аморфной фазе присутствуют обе модификации кобальта: высокотемпературная (ГЦК) и низкотемпературная (ГПУ). Размер нанокристаллов составляет 15-30 nm. При последующей термообработке при более высокой температуре происходит образование равновесных кристаллических фаз.

\section{4. Обсуждение результатов}

Как было сказано выше, исследованиям кристаллизации аморфных сплавов типа Finemet посвящено много работ. Мотивацией этих исследований являлась попытка сформировать нанокристаллическую структуру, обладающую хорошими магнитными свойствами. Как уже отмечалось, аморфные сплавы системы $\mathrm{Fe}-\mathrm{Si}-\mathrm{B}$ обладают хорошими магнитными свойствами, которые могут быть улучшены при частичной кристаллизации аморфной фазы за счет выделения нанокристаллов железа. Однако в силу ряда причин сформировать наноструктуру в этих сплавах только при термообработке не удается. Поэтому был разработан следующий подход. При первичной кристаллизации состав образующихся нанокристаллов отличается от состава аморфного сплава. Это означает, что процесс формирования кристаллов является диффузионным. Для образования кристаллов наноразмера требуется обеспечить высокую скорость зарождения кристаллов и низкую скорость их роста. Для этого в базовый состав $\mathrm{Fe}-\mathrm{Si}-\mathrm{B}$ вводятся небольшие количества меди и ниобия. Медь плохо растворяется в аморфной фазе на основе железа, и кластеры меди служат местами зарождения кристаллов. На начальной стадии кристаллизации этих аморфных сплавов происходит выделение кристаллов твердого раствора кремния в железе $\mathrm{Fe}(\mathrm{Si})$. В решетке железа ниобий не растворяется, и при образовании кристаллов железа атомы ниобия диффундируют от растущего кристалла вглубь аморфной матрицы. Ниобий характеризуется низкой скоростью диффузии, поэтому скорость его перераспределения (отвода от фронта реакции) и определяет скорость роста кристаллов. Таким об- разом был получен первый нанокристаллический сплав на базе $\mathrm{Fe}-\mathrm{Si}-\mathrm{B}\left(\mathrm{Fe}_{73.5} \mathrm{Si}_{13.5} \mathrm{~B}_{9} \mathrm{Nb}_{3} \mathrm{Cu}_{1}\right)$, получивший название типа Finemet [27].

Исследованию структуры и свойств нанокристаллических материалов этого типа посвящено много работ (например, [28]). На начальной стадии кристаллизации аморфных сплавов на основе $\mathrm{Fe}-\mathrm{Si}-\mathrm{B}$ выделяются кристаллы твердого раствора кремния в железе $\alpha$ - $\mathrm{Fe}(\mathrm{Si})$ со структурой $\mathrm{D0}_{3}$, равномерно распределенные в аморфной матрице. Добавление к базовому составу меди и ниобия приводит к ухудшению магнитных свойств. В ряде работ исследовалось влияние легирования разными компонентами на структуру и свойства этих сплавов. Добавление кобальта (частичная замена железа на кобальт) приводит к улучшению высокочастотных свойств и температуры Кюри [29,30], частичная замена железа на марганец способствует заметному повышению температуры кристаллизации и замедляет этот процесс [31,32]. Замещение железа никелем также приводит к небольшому изменению стабильности аморфной фазы и, что более существенно, к увеличению среднего размера кристаллов $[33,34]$. Согласно исследованиям [35] уменьшение размера нанокристаллов и улучшение магнитных свойств наблюдаются при замене атомов железа на другие компоненты в последовательности $\mathrm{Nb}=\mathrm{Ta}>\mathrm{Mo}=\mathrm{W}>\mathrm{V}>\mathrm{Cr}$. Предпринимались исследования влияния замены или изменения концентрации других компонентов сплава. Частичное замещение ниобия титаном способствует расширению температурной области существования фазы $\alpha$ - $\mathrm{Fe}(\mathrm{Si})$, увеличению намагниченности и уменьшению коэрцитивной силы [36], при частичной замене ниобия вольфрамом или молибденом размер нанокристаллов увеличивается [37]. Частичная замена меди на золото облегчает зарождение $\alpha-\mathrm{Fe}(\mathrm{Si})$ фазы, уменьшая энергию активации ее кристаллизации [38], а частичная замена бора на германий приводит к увеличению доли нанокристаллической фазы [39], что способствует улучшению магнитных свойств.

Как отмечалось выше, влияние концентрации компонентов сплава на те или иные магнитные характеристики исследовалось довольно широко. Гораздо меньше публикаций было посвящено изучению изменения фазового состава при изменении химического состава. Нами было установлено, что в сплавах на основе железа, содержащих 0.45-1 at.\% меди, на начальной стадии 
кристаллизации образуется только ОЦК фаза, а при меньшем содержании меди наряду с ОЦК фазой происходит образование нескольких других кристаллических фаз. Следует отметить, что при изменении концентрации меди меняется не только фазовый состав, но и размер нанокристаллов: при уменьшении содержания меди размер нанокристаллов значительно увеличивается, а стабильность аморфной фазы падает. В принципе, этот результат согласуется с положением о введении в аморфную фазу меди для увеличения потенциальных мест зарождения нанокристаллов: чем больше в сплаве меди, тем проще происходит образование нанокристаллов. При одинаковой доле нанокристаллической составляющей размер кристаллов должен быть меньше, что и наблюдается экспериментально. Следует отметить, что аналогичное (хотя и не совеем подобное) явление наблюдалось при кристаллизации аморфных сплавов системы $\mathrm{Al}-$ переходный металл (TM)-редкоземельный металл (RE). Так, в работе [6] было показано, что при гетерогенном зарождении нанокристаллов количество потенциальных мест зарождения нанокристаллов определяется долей „специальных“ мест в аморфной матрице: областей, обеденных редкоземельным компонентом, для сплавов типа Al-TM-RE и кластеров меди, в настоящем случае.

В исследованных сплавах на основе кобальта формирующаяся при кристаллизации структура существенно зависит от концентрации ниобия: при содержании ниобия 2 и более процентов наблюдается образование лишь одной ОЦК кристаллической фазы, при меньшей его концентрации образец является многофазным. Вопрос, является ли эта структура, действительно ОЦК, в настоящее время остается открытым. В работе [22] обсуждался вопрос о том, имеют ли выделяющиеся нанокристаллы ОЦК решетку (пространственная группа $\operatorname{Im} 3 m$ ) или представляют собой выделения фазы со структурой $B 2$ (примитивная кубическая решетка пространственной группы $P m 3 m$ ). Проблема в решении этого вопроса связана с близкими значениями рассеивающей способности атомов железа и кобальта, что сильно затрудняет возможность различить эти фазы. Хотя на рентгенограммах не присутствуют отражения при 37.0, 66.8 и 90.6 градуса, характерные для фазы $B 2$, делать вывод о наличии ОЦК фазы следует с осторожностью. Однако поскольку соответствующих отражений обнаружено не было, в дальнейшем мы будем говорить о нанокристаллах ОЦК фазы.

Образование ОЦК фазы, типичной для сплавов на основе железа, в сплавах на основе кобальта ранее наблюдалось только при достаточно большой концентрации железа (при соотношении Со: Fe, не менее 2:1, например, 65\% Co и $35 \%$ Fe $[20,22])$. В исследованных нами сплавах это соотношение равно примерно 10 : 1. Ранее образования ОЦК фазы при столь малой концентрации железа в сплавах на основе кобальта не наблюдалось. Как было показано выше, образование ОЦК фазы зависит от концентрации ниобия: чем больше содержание ниобия, тем меньше доля других кристаллических фаз, а при концентрации ниобия больше 1 at.\% в аморфной матрице присутствуют нанокристаллы только этой фазы. С увеличением концентрации ниобия резко уменьшается размер нанокристаллов. Если размер нанокристаллов обусловлен скоростью отвода компонентов от фронта реакции (как в случае finemet), то уменьшение размера нанокристаллов при увеличении концентрации ниобия (наиболее медленно диффундирующего компонента) понятно. В то же время зависимость зарождения ОЦК фазы от концентрации ниобия не ясна, как непонятны вообще причины образования фазы с такой структурой. Растворимость ниобия в кобальте небольшая и составляет менее 1 at.\%, при комнатной температуре ниобий практически не растворим в железе [40]. Однако если проанализировать структурные аспекты образования фаз, необходимо отметить следующее. Структура ниобия - ОЦК, пространственная группа Im3m, параметр решетки $a=3.306 \AA$ А. Если сравнить решетки ниобия и образующейся при кристаллизации ОЦК фазы, нетрудно заметить, что в них есть совпадающие межплоскостные расстояния, например, $d_{(310) \mathrm{Nb}}=1.045=d_{(220) \text { Оцк. Естественно предположить, }}$ что кластеры на основе ниобия могут служить потенциальными местами зарождения фазы с такой же, как у ниобия (объемно-центрированной) решеткой. Важной особенностью является и тот факт, что образование ОЦК фазы наблюдалось только при значительной $(7 \%$, рис. 2,3) концентрации железа и ОЦК фазы не было обнаружено при малом содержании железа (0.7 at.\%, рис. 4). Следовательно, для образования ОЦК фазы в исследованной аморфной фазе необходимо присутствие двух элементов, имеющих ОЦК решетку ( $\mathrm{Nb}$ и $\mathrm{Fe}$ ). Важно, что решетки этих двух металлов также имеют некоторые одинаковые межплоскостные расстояния, например, $d_{(220) \mathrm{Nb}}=1.169$ и $d_{(211) \mathrm{Fe}}=1.167$. Возможно, что в аморфной фазе могут присутствовать кластеры переменного состава, содержащие оба этих компонента. Наличие областей, упорядоченных по типу образующихся при кристаллизации фаз, наблюдались в разных аморфных сплавах $[41,42]$. В таком случае причиной формирования ОЦК фазы является наличие областей с родственной кристаллической решеткой и увеличение доли ОЦК оказывается естественно зависящим от концентрации и ниобия, и железа в сплаве.

\section{5. Заключение}

Исследования влияния концентрации легирующего компонента на кристаллизацию аморфных сплавов $\left(\mathrm{Fe}_{73} \mathrm{Si}_{13} \mathrm{~B}_{9}\right)_{1-x-y} \mathrm{Nb}_{x} \mathrm{Cu}_{y}$ и $\left(\mathrm{Co}_{70} \mathrm{Si}_{12} \mathrm{~B}_{9}\right)_{1-x-y} \mathrm{Fe}_{x} \mathrm{Nb}_{y}$ показали следующее:

- образование ОЦК структуры в обеих группах сплавов существенно зависит от концентрации легирующих компонентов: в сплавах на основе $\mathrm{Fe}$, содержащих 0.45 и 1 at.\% меди, и в сплавах на основе кобальта с концентра- 
цией ниобия выше 1 at.\%. на начальной стадии кристаллизации образуются нанокристаллы с ОЦК решеткой;

- средний размер ОЦК нанокристаллов зависит от состава сплава и меняется в диапазоне 16-24 nm в сплавах на основе железа и в диапазоне $14-40 \mathrm{~nm}$ в сплавах на основе кобальта;

- кристаллизация железа с концентрацией меди менее 0.4 at.\% и сплавов кобальта с концентрацией ниобия менее 1 at.\% приводит к одновременному образованию нескольких кристаллических фаз.

На основе анализа полученных данных выдвинуто предположение о зарождении ОЦК нанокристаллов на кластерах $\mathrm{Fe}-\mathrm{Nb}$.

\section{Финансирование}

Исследования проведены в рамках госзадания ИФТТ РАН при частичной финансовой поддержке РФФИ (грант № 19-02-00406).

\section{Конфликт интересов}

Авторы заявляют, что у них нет конфликта интересов.

\section{Список литературы}

[1] D.V. Louzguine, A Inoue. J.Non-Cryst. Solids 352, 3903 (2006).

[2] G.E. Abrosimova, A.S. Aronin, S.V. Dobatkin, I.I. Zverkova, D.V. Matveev, O.G. Rybchenko, E.V. Tatyanin. Phys. Solid State 49, 1034 (2007).

[3] Zs. Kovács, P. Henits, S. Hobor, A. Révész. Rev. Adv. Mater. Sci. 18, 593 (2008).

[4] P. Henits, Zs. Kovács, A. Révész. Rev. Adv. Mater. Sci. 18, 597 (2008).

[5] S. Hobor, A. Revesz, A.P. Zhilyaev, Zs. Kovacs. Rev. Adv. Mater. Sci. 18, 590 (2008).

[6] Г.Е. Абросимова, А.С. Аронин. ФТТ 51, 1665 (2009).

[7] Г. Абросимова, А. Аронин, О. Баркалов, Д. Матвеев, О. Рыбченко, В. Маслов, В. Ткач. ФТТ 53, 215 (2011).

[8] V.I. Tkach, S.G. Rassolov, V.V. Popov, V.V. Maksimov. J. NonCryst. Solids 357, 1628 (2011).

[9] A.N. Petrova, I.G. Brodova, O.A. Plekhov, O.B. Naimark, E.V. Shorokov. Techn. Phys. 59, 989 (2014).

[10] E. Pershina, G. Abrosimova, A. Aronin, D. Matveev. Mater. Lett. 134, 60 (2014).

[11] D.V. Louzguine-Luzgin, A.I. Bazlov, S.V. Ketov, A. Inoue. Mater. Chem. Phys. 162, 197 (2015).

[12] G. Abrosimova, D. Matveev, E. Pershina, A. Aronin. Mater. Lett. 183, 131 (2016).

[13] Г. Абросимова. УФН 181, 1265 (2011).

[14] A.S. Aronin, G.E. Abrosimova, I.I. Zver'kova, D. Lang, R. Luck. J. Non-Cryst. Solids 208, 139 (1996).

[15] S. Spriano, C. Antonione, R. Doglione, L. Battezzati, S. Cardoso, J.C. Soares, M.F. da Silva. Phil. Mag. 76B, 529 (1997).

[16] U. Köster, J. Meinhardt, S. Roos, H. Liebertz. Appl. Phys. Lett. 69, 179 (1996).

[17] L.Q. Xing, J. Eckert, W. Löser, L. Schultz. Appl. Phys. Lett. 74, 664 (1999).
[18] C.F. Li. Appl. Phys. Lett. 77, 528 (2000).

[19] V. Chunchu, G. Markandeyulu. J. Appl. Phys. 113, 17A321 (2013).

[20] R. Xiang, Sh. Zhou, B. Dong, G. Zhang, Z. Li, Y. Wang, Ch. Chang. Progr. Natural Sci. Mater. Int. 24, 649 (2014).

[21] V. Cremaschi, B. Arcondo, H. Sirkin, M. Vazquez, A. Asenjo, J.M. Garcia, G. Abrosimova, A. Aronin. J. Mater. Res. 15, 1936 (2000).

[22] C.F. Conde, J.S. Blazquez, A. Conde. In: Properties and Application of Nanocrystalline Alloys from amorphous Precursor / Ed. B. Idzikowski. Kluwer Academic Publ., The Netherlands (2005). P. 111.

[23] R. Nowosielski, A. Zajdel, S. Lesz, B. Kostrubiec, Z. Stoklosa. Archives Mater. Sci. Eng. 28, 141 (2007).

[24] M. Ohta, Y. Yoshizawa. Appl. Phys. Lett. 91, 062517 (2007).

[25] D.V. Louzguine-Luzgin, A.I. Bazlov, S.V. Ketov, A. Inoue. Mater. Chem. Phys. 162, 197 (2015).

[26] А.А. Русаков. Рентгенография металлов. Атомиздат, М. (1977). $480 \mathrm{c}$.

[27] Y. Yoshizawa, S. Oguma, K. Yamauchi. J. Appl. Phys. 64, 6044 (1988).

[28] M.E. McHenry, M.A. Willard, D.E. Laughlin. Prog. Mater. Sci. 44, 291 (1999).

[29] T. Gheiratmand, H.R. Madaah Hosseini, P. Davami, M. Gjoka, G. Loizos, H. Aashuri. J. All. Compd. 282, 79 (2014).

[30] A.S. Hossein, M. Samadi, H. Alihosseini, H.R. Madaah Hosseini. Thermochim Acta 575, 64 (2014).

[31] N. Bayri, T. Izgi, H. Gencer, P. Sovak, M. Gunes, S. Atalay. J. Non-Cryst. Solids 355, 12 (2009).

[32] J. Balcerski, R. Brzozowski, M. Wasiak, K. Polanski, M. Moneta. Vacuum. Suppl. 1. 83, S182 (2009).

[33] Y. Yoshizawa, S. Fujii, D.H. Ping, M. Ohnuma, K. Hono. Scr. Mater. 48, 863 (2003).

[34] P. Agudo, M. Vazquez. J. Appl. Phys. 97, 023901 (2005).

[35] Y. Yoshizawa, K. Yamauchi. Mater. Sci. Eng. A 133, 176 (1991).

[36] M. Yan, H. Tong, S. Tao, J. Liu, J. Alloy. Compd. 505, 264 (2010).

[37] W. Lu, J. Fan, Y. Wang, B. Yan. J. Magn. Magn. Mater. 322, 2935 (2010).

[38] N. Chau, N.Q. Hoa, N.D. The, L.V. Vu. J. Magn. Magn. Mater. 303, e415 (2006).

[39] D. Muraca, V. Cremaschi, J. Moya, H. Sirkin. J. Magn. Magn. Mater. 320, 1639 (2008).

[40] P.R. Elliot. Constitution of Binary Alloys. First Suppl. McGraw-Hill Book Company, N. Y. (1970). 472 p.

[41] Г.Е. Абросимова, А.С. Аронин, В.Е. Асадчиков, А.В. Серебряков. ФММ 62, 496 (1986).

[42] D.V. Louzguine, H. Kato, H.S. Kim, A. Inoue. J. All. Compd. 359, 198 (2003).

Редактор Т.Н. Василевская 